Medicine Updates Faculty of medicine https://muj.journals.ekb.egdean@med.psu.edu.eg April 2022, volume 9, issue 9

\title{
" Renoprotective Effect of Febuxostat Compared with Allopurinol in Hyperuricemic Chronic Kidney Disease Patients Stage 3 and 4"
}

\section{Authors}

\section{Heba Selim Elshair1; Yasser Ahmed Nienaa1; Rana Ibrahim Koreen1; Noha M Elkholy 2}

${ }^{1}$ Faculty of medicine Alexandria University internal medicine department

${ }^{2}$ Faculty of medicine Alexandria University department of internal medicine 


\section{$\underline{\text { Abstract }}$}

Background: Chronic kidney disease is a heterogeneous group of disorders involving changes in kidney structure and function. For many decades they thought that hyperuricemia causes impairment to renal function through retention of uric acid caused by impaired renal excretion. Allopurinol has been the mainstay therapy for gout and hyperuricemia associated conditions for a long time. Allopurinol has a rare but serious hypersensitivity reaction CKD patients are at higher risk of this complication. Febuxostat drug is a new potent agent which seems to be tolerable in patients involving those who develop Allopurinol sensitivity. It is a non-purine compound; It selectively inhibit xanthine oxidoreductase enzyme

Aim: To assess the renoprotective effect of Febuxostat in comparison with Allopurinol in hyperuricemic CKD patients stage 3 and 4 .

Material and methods: This retrospective study included 300 patients selected from Renal outpatient clinic at Alexandria Main University Hospital and private clinics.

- 150 patients CKD stage $(3,4)$ with hyperuricemia treated with Febuxostat renal modified dose.

- 150 patients CKD stage $(3,4)$ with hyperuricemia treated with Allopurinol renal modified dose.

Results: In Febuxostat group than Allopurinol group at 6 months $(\mathrm{u}=8644.5, \mathrm{p}=0.001)$ and 12 months $(\mathrm{u}=6316.0, \mathrm{p}<0.001)$. At 6 months and 12 months data revealed no significant difference in eGFR slopes between the Febuxostat and Allopurinol groups

Keywords: Chronic Kidney Disease, Hyperuricemia, Allopurinol, Febuxostat.

\section{Introduction}

Chronic kidney disease (CKD) is known to be a global community health problem due to its high prevalence, poor outcomes of treatment and huge cost burden ${ }^{(1)}$ According to the current international guidelines, Chronic kidney disease is a heterogeneous group of disorders involving changes in kidney structure and function.

We define CKD by the occurrence of kidney damage or reduced kidney function for three or more months, regardless of the cause. ${ }^{(2)}$ Kidney damage is referring to pathologic abnormalities, detected by imaging studies, renal biopsy or derived from markers as increased albumin excretion rate in urine of or presence of urinary sediment abnormalities.. 


\section{Staging of CKD}

Staging of CKD is essential to guide management, (Figure 1). ${ }^{(3)}$ Staging enhances risk stratification for the major complications of CKD.

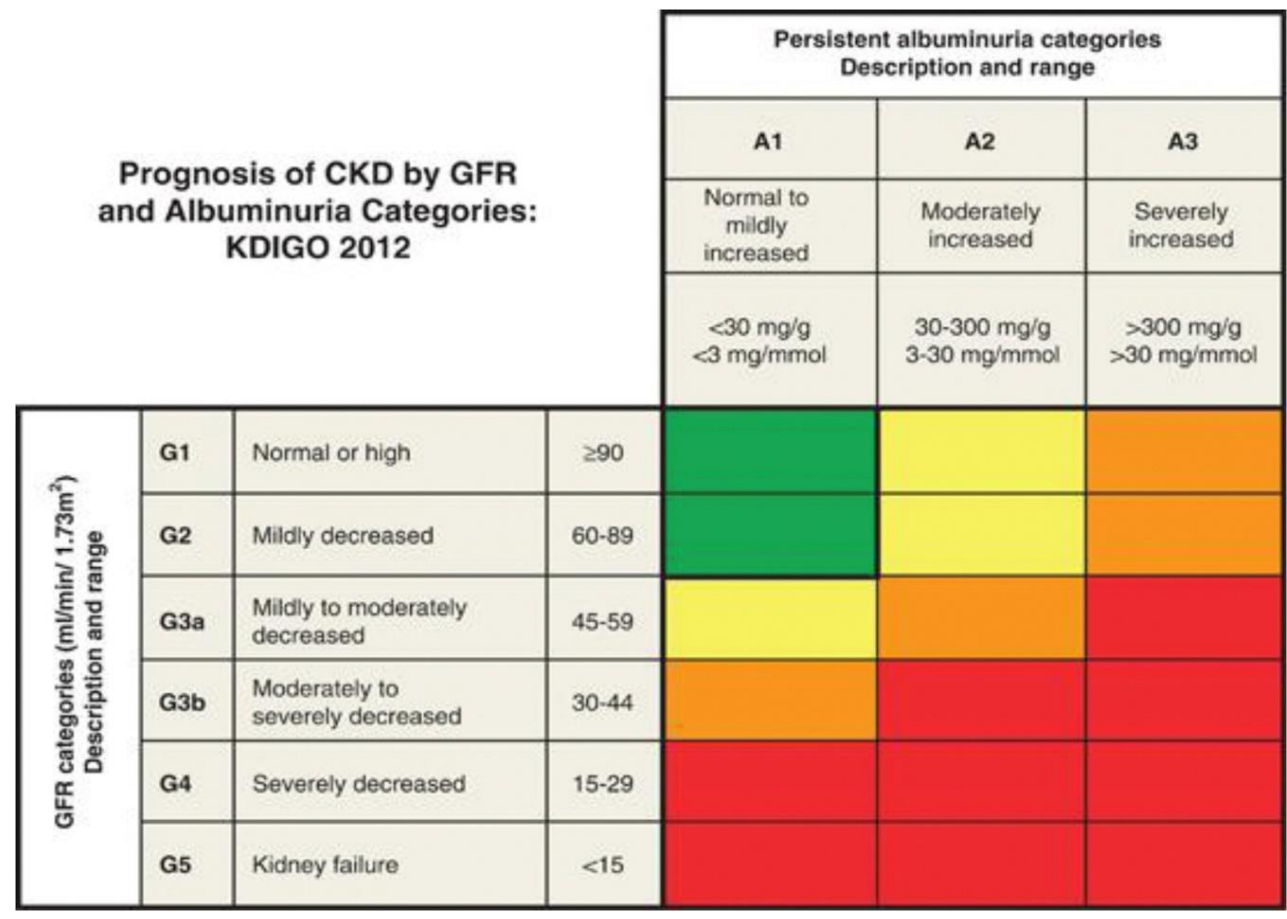

Figure (1): Staging of CKD

Identifying the etiology of CKD enables us to specify the therapy to slow further injury (as, drug toxicity, Diabetes mellitus, auto-immune diseases, urinary tract obstruction, etc.) .

Clinically CKD is usually accidently discovered when we evaluate or manage other medical condition.

\section{Complications of CKD}

Progressive CKD leads to a lot of complications which increase in severity and prevalence at advanced stages. ${ }^{(4,5)}$ These complications affect quality of life and increase morbidity and mortality. Some of these complications are well defined (volume overload, cardiovascular disease, anemia, hypertension, electrolyte disorders, metabolic acidosis and mineral bone disease) so specific measures can be taken, for example anemia is corrected by erythropoiesis stimulating agents. While other complications have less distinct well-defined pathogenesis like fatigue, anorexia, pruritis, nausea, sexual dysfunction and cachexia. 


\section{Management of CKD}

The management involves identifying the reversible causes of renal impairment, slowing CKD progression and treatment of the complications.

It also includes proper arrangement of the renal replacement therapy (RRT). Canadian Society of Nephrology guidelines in 2014 recommend postponing renal replacement therapy in CKD patients without symptoms till eGFR decreases to $6 \mathrm{~mL} / \mathrm{min} / 1.73 \mathrm{~m}^{2}$ or beginning of a clinical indication (which involves fluid retention, uremic manifestations, and refractory acidemia or hyperkalemia). ${ }^{(6)}$ Other factors affecting the time of initiation RRT include severity of existing uremic symptoms, patient education, patient preference, modality selection, and the rate of decline in kidney functions. ${ }^{(6)}$

\section{Hyperuricemia}

\section{Uric acid metabolism:}

There are different factors involved in the metabolism of uric acid which regulate hepatic production, GIT and renal excretion. Exogenous and endogenous purines are metabolized to uric acid as an end product. The exogenous pool significantly varies according to the diet while the endogenous production of uric acid comes mainly from the liver, intestine, tissues such as kidneys, vascular endothelium and muscles. ${ }^{(7)}$

With the help of numerous enzymes adenine and guanine are transformed to uric acid. Firstly, adenosine monophosphate ( AMP) is converted to inosine by two different mechanisms; deamination by deaminase forming inosine monophosphate ${ }^{(8)}$ then dephosphorylation by nucleotidase forming inosine, or dephosphorylation forming adenosine followed by deamination forming inosine. While guanodine monophosphate (GMP) is dephosphorylated by nucleotidase forming guanosine.

Purine-nucleoside-phosphorylase enzyme (PNP) dephosphorylates both inosine and guanosine forming hypoxanthine and guanine respectively. Hypoxanthine oxidation by xanthine oxidase will form xanthine and guanine deamination by guanine deaminase will form xanthine. Lastly xanthine oxidase will oxidate xanthine forming uric acid. (Figure 2) 


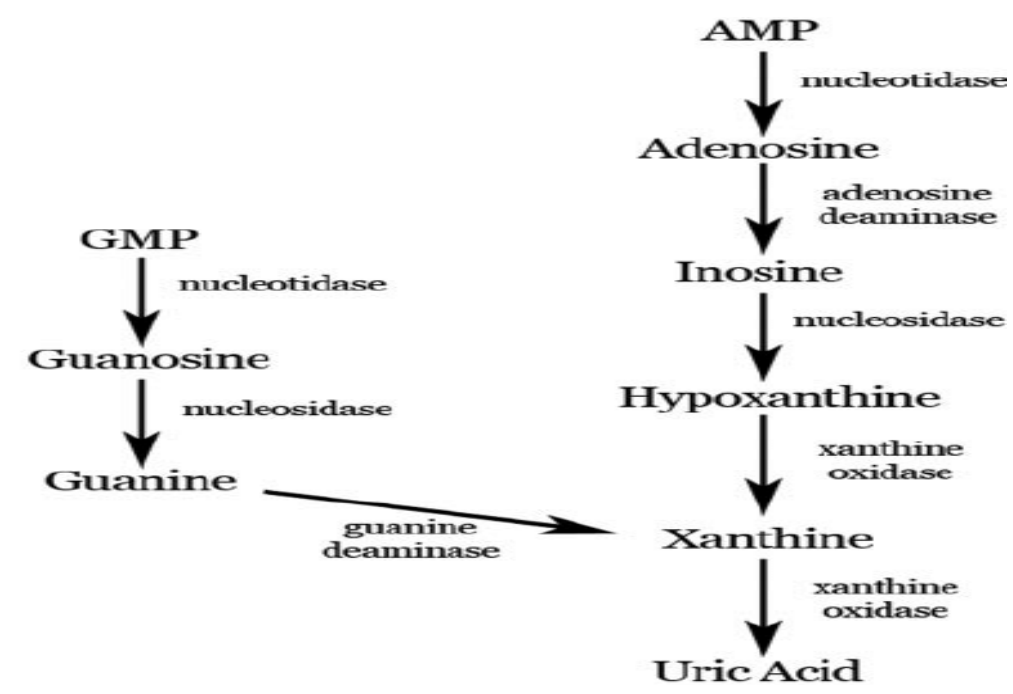

Figure (2): Purine metabolism and production of uric acid

In human urate can't be oxidized to allantoin (more soluble compound) because of the lack of uricase enzyme. Two-thirds of the uric acid load is cleared by the kidneys while gastrointestinal tract eliminates one third. ${ }^{(9)}$

\section{Definition of hyperuricemia:}

There is a lack of universally accepted definition of hyperuricemia. For the clinical and practical scope, we define hyperuricemia as a serum urate level more than $6 \mathrm{mg} / \mathrm{dL},{ }^{(10,11)}$ This number would integrate an estimated threshold of clinical effects of hyperuricemia with the widely recommended goal range of $6 \mathrm{mg} / \mathrm{dL}$ for clinically successful urate-lowering in gout patients.

\section{Epidemiology of hyperuricemia}

Hyperuricemia is a frequent biochemical abnormality that can be detected in 20 to 25 percent of adult men and a smaller percentage of women. ${ }^{(12,13)}$ Due to enhancement of renal uric acid clearance by estrogenic compounds normal adult female uric acid values of reproductive age are lower than those in men. ${ }^{(14)}$ Hyperuricemia in women is usually postponed until after menopause when their values of uric acid increase and correspond to those of men of similar age. ${ }^{(15)}$

\section{Classification of hyperuricemia:}

Hyperuricemia results from excessive urate production, ${ }^{(16)}$ reduced intestinal secretion, ${ }^{(17)}$ absolute or relative impairment of renal urate clearance, ${ }^{(18-20)}$ or a combination 
of these mechanisms. In the kidney, separate sets of transporters mediate reabsorption of filtered urate and secretion of circulating urate across the proximal tubular epithelium; serum urate is determined mainly by the relative balance of these two opposing pathways . Genetically, loss of secretory function or reabsorptive pathway results in hyperuricemia or hypouricemia, respectively. ${ }^{(21,22)}$

There are several factors involved in producing hyperuricemia including environmental factors (drug and diet), comorbid disease-related, and genetic, so the former categorization of hyperuricemia to primary or secondary has given way to the recognition of hyperuricemia as arising from multiple pathways that impact urate production and/or uric acid clearance.

For many decades they thought that hyperuricemia causes impairment to renal function through the retention of uric acid caused by impaired renal excretion until 2002, Kang et al induced hyperuricemia in experimental rats and revealed that it was associated with increase renal renin and cyclooxygenase 2 expression mainly in the pre glomerular arterial vessels reaching the conclusion that hyperuricemia itself contribute to the impairment in renal functions through acceleration of hypertension and vascular disease. Afterwards multiple studies were performed to identify the effect of urate in the progression of renal disease many of them concluded that high urate levels induce oxidative stress and endothelial dysfunction resulting in accelerating the systemic and glomerular hypertension and progression of CKD. ${ }^{(23,24)}$ Also uric acid was found to produce epithelial to mesenchymal transition in the tubular cells, which was known to be a principal contributor to the progression of renal fibrosis. ${ }^{(25)}$

In another important study Mazzali et al found that hyperuricemia induced hypertension and mild tubulointerstitial injury and uric acid lowering prevent development of hypertension and mitigate the decline of renal functions. ${ }^{(25)}$

\section{Management of hyperuricemia:}

Firstly, the reversible causes of hyperuricemia should be identified. All patients should be advised for an adequate life style modifications (weight loss, decrease purine intake, stop alcohol, control diabetes if present) and revision their medications to identify those which may cause hyperuricemia. $^{(26,27)}$

\section{The need of pharmacologic urate-lowering therapy is determined as the following;}

The main indications for pharmacologic urate-lowering therapy (ULT) in gout patients are:

- Gout flares which are frequent and disabling.

- Recurrent uric acid nephrolithiasis despite treatment with hydration and urinary 
alkalization.

- Tophi in subchondral bone or soft tissues

- Gout with CKD (eGFR $<60 \mathrm{~mL} /$ minute $/ 1.73 \mathrm{~m}^{2}$ ).

- Clinical or imaging of structural joint damage (gouty arthropathy or gouty bone erosion).

\section{Asymptomatic hyperuricemia:}

There is lack of adequate evidence for routine use of pharmacologic management for most patients with asymptomatic hyperuricemia and there is a need for further clinical trials

in this area, ${ }^{(28,29)}$ despite the high prevalence of this biochemical aberration. Nevertheless, in a few situations discussed below, pharmacologic intervention appears wanted.

\section{Sustained marked hyperuricemia:}

Urate-lowering therapy benefits or potentially benefits selected patients with sustained marked asymptomatic hyperuricemia rather than only providing advice regarding lifestyle, diet, and managing comorbidities alone. Examples of those who complain from sustained marked hyperuricemia are patients with purine and/or uric acid overproduction due to inherited monogenic defects in purine metabolism, or clinical disorders associated with rapid cell turnover, and individuals whose hyperuricemia and hyperuricosuria results from genetic polymorphisms in uric acid transporter genes which result in impairment of urate clearance. ${ }^{(30)}$

\section{Marked asymptomatic hyperuricosuria:}

A trial of restricted dietary purine and purine precursor intake should precede Allopurinol initiation in patients with asymptomatic hyperuricemia and hyperuricosuria (urinary urate excretion $>1100 \mathrm{mg}$ daily), with the aim of reduction daily renal urinary urate excretion $<1000 \mathrm{mg}$.

Failure to reach this goal leads to either of two alternatives for stone prophylaxis:

- First, hydration (>2 liters of fluids daily) and urinary alkalinization (target: urinary $\mathrm{pH} \geq 6.5$ for at least several hours daily)

- Second, hydration and Allopurinol. ${ }^{(31,32)}$

3. Hyperuricemia non crystal disease: (Hyperuricemia and conditions unassociated with crystal deposition such as CKD, hypertension and cardiovascular disease):

As discussed before lack of an established causal role of hyperuricemia in CKD, ${ }^{(28,29)}$ 
and the other associated disorders, has restrained enthusiasm in the United States for prophylactic urate lowering therapy in most persons with asymptomatic hyperuricemia. However, experts in some countries (for example, Japan) recommend anti hyperuricemic drug therapy for asymptomatic hyperuricemic individuals, especially when associated with diseases like DM or hypertension. ${ }^{(33)}$

\section{Pharmacologic urate-lowering therapy}

\section{There are several classes of urate-lowering therapies:}

- Xanthine oxidase inhibitors, including Allopurinol and Febuxostat

- Uricosuric agents, including probenecid, benzbromarone, and lesinurad

- Uricase, available as pegloticase and rasburicase

Xanthine oxidase inhibitors; They Inhibit xanthine oxidase, the enzyme responsible for conversion hypoxanthine to xanthine to uric acid so decreases uric acid

Allopurinol has been the mainstay therapy for gout and hyperuricemia associated conditions for a long time. ${ }^{(34,35)}$ Theoretically Allopurinol in effective dose can lower uric acid to its normal values, but it isn't easy to prescribe high doses in renal patients for fear of retention of metabolite oxipurinol. ${ }^{(36)}$ Allopurinol has a rare but serious hypersensitivity reaction which includes fever, rash, hepatic abnormalities, acute renal failure, and eosinophilia. ${ }^{(36)}$ This seems to be dose-dependent and when occur can lead to 20 percent mortality. ${ }^{(35)} \mathrm{CKD}$ patients are at higher risk of this complication. ${ }^{(34)}$

Cutaneous side effects which includes; toxic epidermal necrolysis Stevens-Johnson syndrome and hypersensitivity syndrome are closely linked to HLA-B*5801 allele among Han Chinese patients, so screening this allele in high risk patients could be beneficial. ${ }^{(37)}$

Due to frequent failure of Allopurinol to maintain target serum uric acid and intolerance in some patients, there is a need to develop an alternative potent and safe urate lowering drug.

Febuxostat drug is a new potent agent which seems to be tolerable in patients involving those who develop Allopurinol sensitivity. It is a non-purine compound; It selectively inhibit xanthine oxidoreductase enzyme.

Xanthine oxidoreductase is synthesized as Xanthine dehydrogenase which can easily be converted to xanthine oxidase by oxidation of sulfhydryl residues or by proteolysis in mammals. While Allopurinol and Oxypurinol inhibit the oxidized form of xanthine oxidase 
(XO), Febuxostat can inhibit both the reduced and oxidized forms of XO. ${ }^{(38)}$ Febuxostat has a high affinity to bind with the enzyme in a molecular channel leading to the active catalytic site (molybdenum-pterin), where Allopurinol expresses a comparably weak competitive inhibition. ${ }^{(38)}$

As stated above, purines (cytosine and guanine) are metabolized forming hypoxanthine which oxidized to xanthine by xanthine oxidase and again to uric acid which is excreted mainly in the urine. ${ }^{(39)}$ Therefore, an analogue of purines can then compete with xanthine and hypoxanthine for metabolism by xanthine oxidase. This is the difference between Allopurinol and Febuxostat. Allopurinol and its metabolites are both purines and pyrimidines structural analogues. ${ }^{(40,41)}$ they inhibit orotidine-5-monophosphate decarboxylase (OMPDC) and purine nucleoside phosphorylase (PNP) which are needed in both purines and pyrimidines metabolism that will be eventually used for the synthesis of both DNA and RNA. ${ }^{(42,43)}$ It has been speculated that Allopurinol's side effects attributed to these other pathways. On the other hand Febuxostat isn't purines nor pyrimidines structural analogue, it only inhibits xanthine oxidase and doesn't affect the activity of these other pathways. ${ }^{(44,45)}$

Febuxostat is metabolized in the liver. Among patients having mild to moderate hepatic impairment (Child-Pugh Classes A and B) the pharmacokinetics of Febuxostat aren't affected. ${ }^{(46)}$ In the kidneys less than 5 percent of the dose is unchanged eliminated in the urine. In patients having severe renal impairment there is increase in the area under the timeconcentration curve by a factor of 1.8 , but in patients with mild to moderate renal dysfunction no dose adjustment is needed. ${ }^{(47)}$

The FDA recently released a public safety alert in response to the CARES study results; they reported no marked difference between Febuxostat and Allopurinol regarding occurrence of major cardiovascular events (MACE) in patients with gout having cardiovascular comorbidities at baseline however data revealed that cardiovascular mortality and all-cause mortality were higher in Febuxostat than Allopurinol. ${ }^{(48)}$

Therefore, we need more randomized controlled trials targeting cardiovascular safety as its primary outcome during usage of Febuxostat drug

\section{Aim of the Work}

\section{The aim of the present work was:}

1. To assess the renoprotective effect of Febuxostat in comparison with Allopurinol in hyperuricemic CKD patients stage 3 and 4. 
2. To compare the changes in estimated glomerular filtration rate in hyperuricemic CKD patients stage 3 and 4, treated with Febuxostat and Allopurinol.

3. To copmare the urate lowering effect of Febuxostat and Allopurinol rate in hyperuricemic CKD patients stage 3 and 4 .

4. To determine the association between xanthine oxidase inhibitors and occurrence of major adverse cardiovascular events in hyperuricemic CKD patients stage 3 and 4.

\section{Patients}

This retrospective study included 300 patients selected from Renal outpatient clinic at Alexandria Main University Hospital and private clinics.

- 150 patients CKD stage $(3,4)$ with hyperuricemia treated with Febuxostat renal modified dose.

- 150 patients CKD stage $(3,4)$ with hyperuricemia treated with Allopurinol renal modified dose.

\section{$>$ Inclusion criteria:}

- Adult patients (age above 18years) with CKD stage 3,4 having hyperuricemia treated with Febuxostat or Allopurinol for more than one year.

\section{Exclusion criteria:}

- Patients on dialysis

- Patients having kidney transplantation.

- Patient having malignancy.

- Patients on treatment known to induce hyperuricemia (Cyclosporine, Tacrolimus, Pyrazinamide and laxative abuse)

\section{Methods}

Data of the patients were collected from Alexandria main university hospital clinics:

1- History taking (cause and duration of renal impairment, hypertention, duration of hyperuricemia, history of stones, hyperlipidemia and cardiovascular disease).

2- Clinical examination (stressing on presence of tophaceous gout, examination of joints and measuring blood pressure). 
3- Laboratory investigations:

- Serum urea, serum creatinine and estimated GFR (e.GFR) by MDRD equation every three months. ${ }^{(49,50)}$

- Serum uric acid every three months. ${ }^{(51)}$

- Urine analysis every three months. ${ }^{(49)}$

- Proteinuria by dipstick test. ${ }^{(49)}$

4- Imaging:

- Ultrasound abdomen and pelvis if needed.$^{(52)}$

5- Using medical records to evaluate the effect of using urate-lowering therapy either Allopurinol or Febuxostat for one year retrospectively. 
1- Primary outcome:

- Changes in eGFR in the Febuxostat and Allopurinol groups.

2- Secondary outcomes:

- Changes in serum uric acid level.

- Changes in albumin creatinine ratio.

- Major adverse cardiovascular event (defined as cardiovascular death, nonfatal stroke, non-fatal myocardial infarction (MI), and unstable angina requiring urgent coronary revascularization).

\section{Statistical analysis of the data}

After completing data collection, the raw data was revised, coded and transformed into coding sheets. Data accuracy and reliability were maintained by double entry process. All data entry was performed by the researcher using Statistical Package for Social Sciences (SPSS ver. 22) using a personal computer. Output drafts were tested against revised coded data for typing and spelling mistakes. Lastly, analysis and interpretation of data were performed. The following statistical methods were used:

a) Descriptive statistics as tabular and graphical presentations were used to describe different characteristics of patients included in the study. For quantitative variable; mean and standard deviation or median and IQR were calculated.

b) Analytic statistics were also used which included:

- Chi -square test $\left(\chi^{2}\right)$ was used for categorical variables, to compare between two or more different groups.

- Independent t-test for normally distributed quantitative variables to compare between means in two different studied groups.

- Fisher Exact test was used for correction for chi-square to compare between different groups when $25 \%$ of cells or more have expected count less than 5.

- Mann-Whitney U test is non-parametric test for abnormally distributed quantitative variables to compare between means in two different studied groups.

- Wilcoxon signed rank test is non-parametric test for abnormally distributed quantitative variables to compare between baseline mean and mean of outcome in the same studied group.

(The significance of the results was at the 0.05 level of significance). 


\section{Results}

This study is a retrospective cohort study, conducted on 300 patients selected from Renal outpatient clinic at Alexandria Main University Hospital and private clinics. 150 patients using Febuxostat drug (Febuxostat group) and 150 patients using Allopurinol drug (Allopurinol group).

\section{Demographic data}

Table 1 shows the distribution of the studied groups according to gender and age.

- Regarding gender the study included 154 males (51.3\%) and 146 females (48.7\%). There were statistically significant differences between the Febuxostat group (55.3\% of patients were females and $44.7 \%$ were males) and between the Allopurinol group (58\% of patients were males while $42 \%$ were females $),\left(\chi^{2}=5.337, p=0.021\right)$.

- Regarding age, there was no significant difference between the studied groups; the mean age in the Febuxostat group was $(61.54 \pm 12.40)$, while in the Allopurinol group the mean age was $(60.83 \pm 13.57)$.

- Table (1): Comparison between the studied groups according to demographic data

\begin{tabular}{|c|c|c|c|c|c|c|}
\hline & \multicolumn{2}{|c|}{$\begin{array}{l}\text { Febuxostat } \\
\qquad(n=150)\end{array}$} & \multicolumn{2}{|c|}{$\begin{array}{l}\text { Allopurinol } \\
\qquad(\mathrm{n}=\mathbf{1 5 0})\end{array}$} & \multirow[t]{2}{*}{ Test of Sig. } & \multirow[t]{2}{*}{$\mathbf{P}$} \\
\hline & No. & $\%$ & No. & $\%$ & & \\
\hline \multicolumn{7}{|l|}{ Sex } \\
\hline Male & 67 & 44.7 & 87 & 58.0 & $\chi^{2}=5.337^{*}$ & $0.021^{*}$ \\
\hline Female & 83 & 55.3 & 63 & 42.0 & & \\
\hline \multicolumn{7}{|l|}{ Age (years) } \\
\hline Min. - Max. & \multicolumn{2}{|c|}{$25.0-91.0$} & \multicolumn{2}{|c|}{$26.0-90.0$} & & \\
\hline Mean \pm SD & \multicolumn{2}{|c|}{$61.54 \pm 12.40$} & \multicolumn{2}{|c|}{$60.83 \pm 13.57$} & $\mathrm{t}=0.471$ & 0.638 \\
\hline Median (IQR) & \multicolumn{4}{|c|}{$64.0(55.0-67.0) 62.0(54.0-68.0)$} & & \\
\hline
\end{tabular}


- $\quad$ p: $\mathrm{p}$ value for comparing between the studied groups

- *: Statistically significant at $\mathrm{p}<0.05$

\section{Comorbidities, causes and staging of CKD:}

- Table 2 shows that among all patients HTN was the most common comorbidity (90\%), combined DM with HTN in (44\%), polycystic kidney disease (APKD) was found in (3.7\%), unknown etiology in $(4.7 \%)$.

- Regarding the staging table 2 shows that $(43.3 \%)$ of patients were in stage 3 while $56.7 \%$ ) were in stage 4.

- Table (2): Comparison between the studied groups according to the comorbidities and CKD stage

\begin{tabular}{|c|c|c|c|c|c|c|c|c|}
\hline & \multicolumn{2}{|c|}{$\begin{array}{l}\text { Febuxostat } \\
\qquad(n=150)\end{array}$} & \multicolumn{2}{|c|}{$\begin{array}{l}\text { Allopurinol } \\
\qquad(\mathrm{n}=\mathbf{1 5 0})\end{array}$} & \multicolumn{2}{|c|}{$\begin{array}{c}\text { Total } \\
(\mathbf{n = 3 0 0})\end{array}$} & \multirow[t]{2}{*}{$\chi^{2}$} & \multirow[t]{2}{*}{$\mathbf{P}$} \\
\hline & No. & $\%$ & No. & $\%$ & No. & $\%$ & & \\
\hline $\begin{array}{l}\text { Cause of CKD } \\
\text { Type } 2 \text { diabetes mellitus } \\
\text { (DM) only } \\
\text { Hypertension (HTN) only } \\
\text { Type } 2 \text { diabetes mellitus } \\
\text { (DM) + Hypertension (HTN) } \\
\text { Polycystic kidney disease } \\
\text { (PKD) }\end{array}$ & $\begin{array}{l}62 \\
71\end{array}$ & $\begin{array}{l}41.3 \\
47.3\end{array}$ & $\begin{array}{l}2 \\
76\end{array}$ & 50.7 & $\begin{array}{r}138 \\
132\end{array}$ & $\begin{array}{l}46 \\
44\end{array}$ & 3.612 & 0.461 \\
\hline $\begin{array}{l}\text { CKD stage } \\
\text { III } \\
\text { IV }\end{array}$ & $\begin{array}{l}69 \\
81\end{array}$ & $\begin{array}{l}46.0 \\
54.0\end{array}$ & $\begin{array}{l}61 \\
89\end{array}$ & $\begin{array}{l}40.7 \\
59.3\end{array}$ & $\begin{array}{l}130 \\
170\end{array}$ & $\begin{array}{l}43.3 \\
56.7\end{array}$ & 0.869 & 0.351 \\
\hline
\end{tabular}


Table 3 shows laboratory parameters at the baseline of the study (lab result at the first time visit to the clinic):

The mean of the baseline serum creatinine in Febuxostat group was $2.36 \pm 0.86 \mathrm{mg} / \mathrm{dl}$, and for the patients in Allopurinol group was of $2.46 \pm 0.84 \mathrm{mg} / \mathrm{dl}$, there was no statistically significant difference between the two groups.

- The eGFR in Febuxostat group ranged from 15.0 to $59.0 \mathrm{~mL} / \mathrm{min} / 1.73 \mathrm{~m}^{2}$ with a mean of $30.46 \pm 12.05 \mathrm{~mL} / \mathrm{min} / 1.73 \mathrm{~m}^{2}$, and for the patients in Allopurinol group it ranges from 15.0 - 59.90 with a mean of $29.77 \pm 11.82 \mathrm{~mL} / \mathrm{min} / 1.73 \mathrm{~m}^{2}$.

- Regarding the baseline uric acid; there was a statistically significant difference between Febuxostat group and Allopurinol group $(\mathrm{u}=9310.5, \mathrm{p}=0.010)$. In the Febuxostat group, the mean was $8.04 \pm 2.34 \mathrm{mg} / \mathrm{dl}$; which was significantly higher than the Allopurinol group. The mean of Baseline uric acid of the patients in Allopurinol group was $7.29 \pm 2.34 \mathrm{mg} / \mathrm{dl}$.

Table (3) Comparison between the studied groups according to lab results at the baseline (lab result at the first time visit to the clinic)

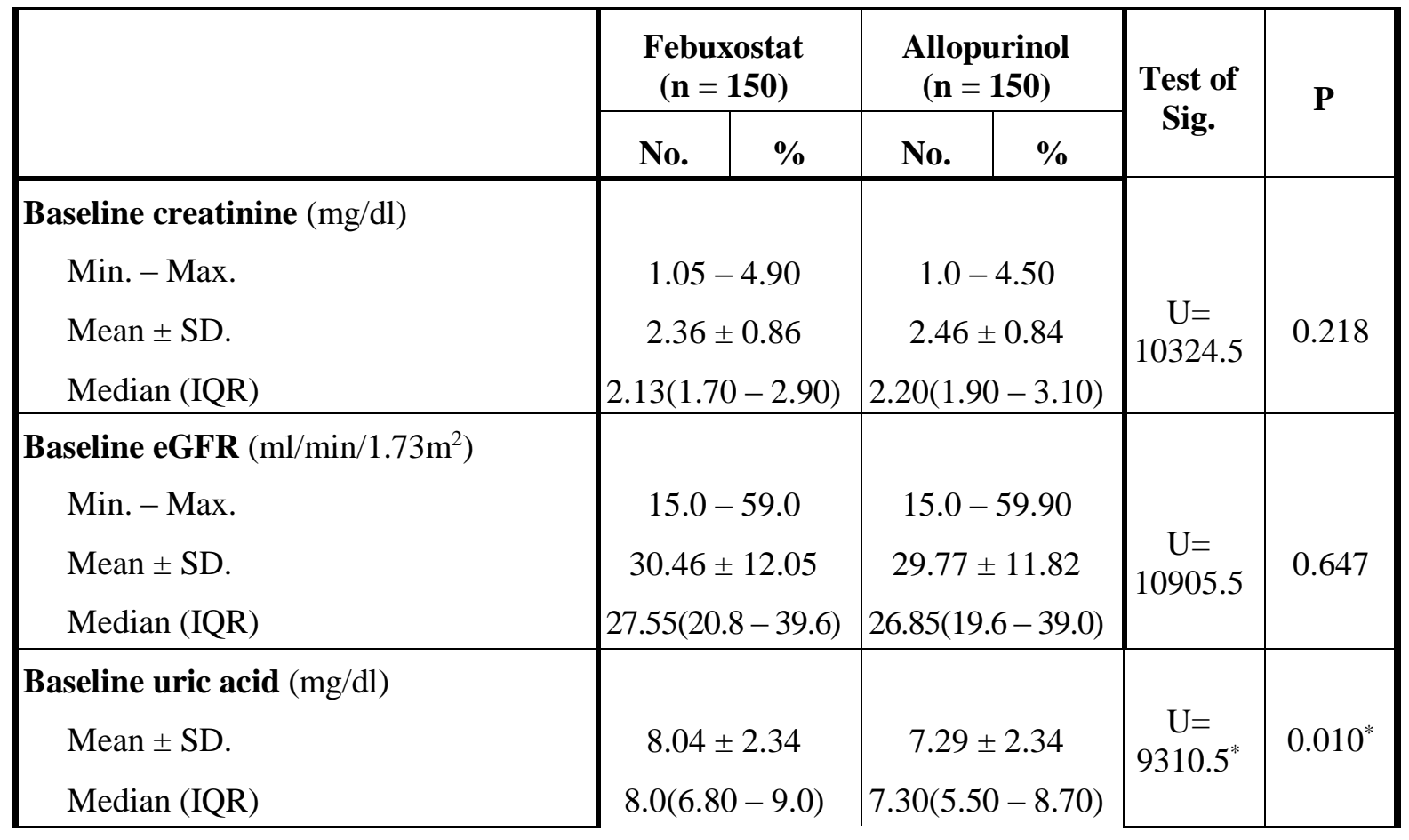

- $\chi^{2}:$ Chi square test

FE: Fisher Exact

- U: Mann Whitney test

- $\quad \mathrm{p}$ : $\mathrm{p}$ value for comparing between the studied groups

- *: Statistically significant at $\mathrm{p}<0.05$ 
Changes in eGFR in the Febuxostat and Allopurinol groups over 12 months:

Table 4 show eGFR changes over time in patients after continuous use of drugs; at 6 months and 12 months data revealed no significant difference in eGFR slopes between the Febuxostat and Allopurinol groups ( difference, 0.85 ; 95\% CI, -2.35 to 4.06; $\mathrm{P}=0.461$ ), (difference, $3.66 ; 95 \% \mathrm{CI}, 0.13$ to $7.19 ; \mathrm{P}=0.100$ ), respectively.

Table (4): Changes in eGFR in the Febuxostat and Allopurinol groups over 12 months

\begin{tabular}{|c|c|c|c|c|c|}
\hline $\begin{array}{c}\text { eGFR } \\
\left(\mathrm{ml} / \mathrm{min} / 1.73 \mathrm{~m}^{2}\right)\end{array}$ & $\begin{array}{l}\text { Febuxostat } \\
\qquad(n=150)\end{array}$ & $\begin{array}{l}\text { Allopurinol } \\
\qquad(\mathrm{n}=\mathbf{1 5 0})\end{array}$ & $\begin{array}{l}\text { Difference } \\
\text { (95\% C.I of } \\
\text { difference) }\end{array}$ & $\mathbf{U}$ & p1 \\
\hline $\begin{array}{l}\text { Baseline } \\
\text { Min. - Max. } \\
\text { Mean } \pm \text { SD. } \\
\text { Median (IQR) }\end{array}$ & $\begin{array}{c}15.0-59.0 \\
30.46 \pm 12.05 \\
27.55(20.8-39.6)\end{array}$ & $\begin{array}{c}15.0-59.90 \\
29.77 \pm 11.82 \\
26.85(19.6-39.0)\end{array}$ & $\begin{array}{c}068 \\
(-2.03 \text { to } 3.39)\end{array}$ & 10905.5 & 0.647 \\
\hline $\begin{array}{c}\text { Month } 6 \\
\text { Min. - Max. } \\
\text { Mean } \pm \text { SD. } \\
\text { Median (IQR) }\end{array}$ & $\begin{array}{c}7.37-92.0 \\
31.26 \pm 14.08 \\
29.85(20.8-39.9)\end{array}$ & $\begin{array}{c}10.20-87.50 \\
30.41 \pm 14.16 \\
27.88(20.0-37.3)\end{array}$ & $\begin{array}{c}0.85 \\
(-2.35 \text { to } 4.06)\end{array}$ & 10696.5 & 0.461 \\
\hline $\begin{array}{l}\text { Month } 12 \\
\text { Min. - Max. } \\
\text { Mean } \pm \text { SD. } \\
\text { Median (IQR) }\end{array}$ & $\begin{array}{c}7.10-91.0 \\
33.22 \pm 16.92 \\
32.05(19.6-44.7)\end{array}$ & $\begin{array}{c}8.10-76.0 \\
29.56 \pm 14.02 \\
26.15(18.5-39.0)\end{array}$ & $\begin{array}{c}3.66 \\
(0.13 \text { to } 7.19)\end{array}$ & 10013.0 & 0.100 \\
\hline $\mathrm{Z}(\mathbf{p 2})$ & $1.248(0.212)$ & $0.285(0.776)$ & & & \\
\hline
\end{tabular}

U: Mann Whitney test

Z: Wilcoxon signed ranks test

p1: $\mathrm{p}$ value for comparing between the studied groups

p2: $\mathrm{p}$ value for comparing between Baseline and study end in each group 
Changes in uric acid in the Febuxostat and Allopurinol groups over 12 months:

Table 5 shows there was reduction in uric acid among all patient in both groups. Uric acid level decreased from $8.04 \pm 2.34 \mathrm{md} / \mathrm{dl}$ (baseline) to $5.37 \pm 1.59 \mathrm{mg} / \mathrm{dl}, 4.66 \pm 1.68 \mathrm{mg} / \mathrm{dl}$ at 6, 12 months respectively in the Febuxostat group and for the Allopurinol group it decreased from $7.29 \pm 2.34 \mathrm{mg} / \mathrm{dl}$ (baseline) to $6.02 \pm 1.63,5.94 \pm 1.51 \mathrm{mg} / \mathrm{dl}$ at $6,12 \mathrm{months}$ respectively. Reduction in uric acid level was significantly higher in Febuxostat group than Allopurinol group at 6 months $(\mathrm{u}=8644.5, \mathrm{p}=0.001)$ and 12 months $(\mathrm{u}=6316.0, \mathrm{p}<0.001)$.

Table (5): Changes in uric acid in the Febuxostat and Allopurino groups over 12 months

\begin{tabular}{|c|c|c|c|c|c|}
\hline $\begin{array}{c}\text { Uric acid } \\
(\mathrm{mg} / \mathrm{dl})\end{array}$ & $\begin{array}{l}\text { Febuxostat } \\
(n=150)\end{array}$ & $\begin{array}{l}\text { Allopurinol } \\
(\mathbf{n}=\mathbf{1 5 0})\end{array}$ & $\begin{array}{c}\text { Difference }(95 \% \text { C.I } \\
\text { of difference) }\end{array}$ & $\mathbf{U}$ & P1 \\
\hline $\begin{array}{l}\text { Baseline } \\
\text { Mean } \pm \text { SD. } \\
\text { Median (IQR) }\end{array}$ & $\begin{array}{c}8.04 \pm 2.34 \\
8.0(6.8-9.0)\end{array}$ & $\begin{array}{c}7.29 \pm 2.34 \\
7.30(5.5-8.7)\end{array}$ & $\begin{array}{c}0.75 \\
(0.22 \text { to } 1.28)\end{array}$ & $9310.5 *$ & $0.010^{*}$ \\
\hline $\begin{array}{l}\text { Month } 6 \\
\text { Mean } \pm \text { SD. } \\
\text { Median (IQR) }\end{array}$ & $\begin{array}{c}5.37 \pm 1.59 \\
5.42(4.0-6.5)\end{array}$ & $\begin{array}{c}6.02 \pm 1.63 \\
6.0(5.0-7.0)\end{array}$ & $\begin{array}{c}-0.65 \\
(-1.02 \text { to }-0.29)\end{array}$ & $8644.5 *$ & $0.001 *$ \\
\hline $\begin{array}{l}\text { Month } 12 \\
\text { Mean } \pm \text { SD } \\
\text { Median (IQR) }\end{array}$ & $\begin{array}{c}4.66 \pm 1.68 \\
4.45(3.20-5.90)\end{array}$ & $\begin{array}{c}5.94 \pm 1.51 \\
6.0(5.0-7.0)\end{array}$ & $\begin{array}{c}-1.28 \\
(-1.64 \text { to }-0.92)\end{array}$ & $6316.0 *$ & $<0.001 *$ \\
\hline $\mathrm{Z}(\mathbf{p} 2)$ & $9.778^{*}\left(<0.001^{*}\right)$ & $5.789^{*}\left(<0.001^{*}\right)$ & & & \\
\hline
\end{tabular}

U: Mann Whitney test

$\mathrm{Z}$ : Wilcoxon signed ranks test

$\mathrm{p} 1$ : $\mathrm{p}$ value for comparing between the studied groups

$\mathrm{p} 2$ : $\mathrm{p}$ value for comparing between Baseline and study end in each group

*: Statistically significant at $\mathrm{p}<0.05$ 


\section{Occurrence of major adverse cardiac events (MACE):}

Table 6 shows that there was no significant difference between Febuxostat and Allopurinol groups regarding occurrence of MACE. one patient in Febuxostat group and three patients in Allopurinol group developed major adverse cardiac events.

In the Febuxostat group one patient developed the following event:

1) Anginal pain requiring PCI and stent insertion.

\section{In Allopurinol group 3 patients developed the following events:}

1. Unstable angina for cardiac catheter but patient refused.

2. Non-STEMI with 2 stents insertion.

\section{Inferior MI.}

Table (6): Comparison between the studied groups according to occurrence of MACE

\begin{tabular}{|c|c|c|c|c|c|c|}
\hline & \multicolumn{2}{|c|}{$\begin{array}{l}\text { Febuxostat } \\
\qquad(n=150)\end{array}$} & \multicolumn{2}{|c|}{$\begin{array}{l}\text { Allopurinol } \\
\qquad(\mathrm{n}=\mathbf{1 5 0})\end{array}$} & \multirow[t]{2}{*}{$\chi^{2}$} & \multirow[t]{2}{*}{ FEp } \\
\hline & No. & $\%$ & No. & $\%$ & & \\
\hline$\overline{\mathrm{MACF}}$ & & & & & & \\
\hline $\begin{array}{l}\text { No } \\
\text { Yes }\end{array}$ & 149 & $\begin{array}{r}99.3 \\
0.7\end{array}$ & $\begin{array}{c}147 \\
3\end{array}$ & $\begin{array}{r}98.0 \\
2.0\end{array}$ & 1.014 & 0.622 \\
\hline
\end{tabular}

$\chi^{2}$ : Chi square test FE: Fisher Exact

$\mathrm{p}$ : $\mathrm{p}$ value for comparing between the studied groups

\section{Discussion}

Hyperuricemia is known to be a common biochemical aberration, detected in 20 percent to 25 percent of adult men and a lesser percentage of women in some populations. ${ }^{(12,13)}$ Hyperuricemia has been associated with $\mathrm{CKD} .{ }^{(53,54)}$ Previous studies indicated that hyperuricemia contributes to the development and progression of chronic kidney disease, cardiovascular and cerebrovascular diseases. ${ }^{(55,56)}$ In this regard, a reduction in serum urate levels in CKD patients seems to play a significant role in postponing progression of renal disease. While 
multipe studies ${ }^{(57,58,59)}$ have assessed and supported the renoprotective effect of urate reduction in hyperuricemic CKD patients, we have many questions needed to be answered one of them is choosing the appropriate drug to treat hyperuricemia.

Allopurinol, an inhibitor of XO, is a convential urate lowering drug which has been widely used in gout patients for years. It is usually well tolerated and when used in proper doses effectively reduces serum uric acid. However, Allopurinol has a rare but serious adverse reactions like hypersensitivity reactions involving Stevens-Johnson syndrome, ${ }^{(60)}$ which is more common in CKD patients. Therefore, physicians may hesitate to prescribe or upgrade Allopurinol dose in CKD patients leading to inadequate hyperuricemia control. ${ }^{(61)}$

Febuxostat, an alternative agent to Allopurinol, was introduced in 2008. It selectively inhibits xanthine oxidase and it reduces urate level more effectively than Allopurinol ${ }^{(62)}$ Its metabolism occurs in the liver resulting in unnecessary dose adjustment in patients having mild to moderately impaired renal function. ${ }^{(63)}$ In addition, it was safe in most gout patients having Allopurinol sensitivity reactions. ${ }^{(64)}$

Our study aimed to assess the renoprotective of Febuxostat in comparison with Allopurinol, which drug is more effective in lowering uric acid level and to observe the association between the use of xanthine oxidase inhibitors and occurrence of MACE (major adverse cardiovascular event) in hyperuricemic CKD patients stage 3 and 4.

The present study included 300 hyperuricemic CKD patients (150 patients received Febuxostat drug, 150 patients received Allopurinol drug) who were attending Renal outpatient clinic at Alexandria Main University Hospital and private clinics. We included CKD patients stage 3,4 (age above 18years) having hyperuricemia treated with Febuxostat or Allopurinol for more than one year. While patients on dialysis, having kidney transplantation, having malignancy and those on treatment known to induce hyperuricemia (Thiazide, Cyclosporine, Tacrolimus, Pyrazinamide and laxative abuse) were excluded from the study.

In the present study regarding gender, we included 154 males $(51.3 \%)$ and 146 females (48.7\%). There were statistically significant differences between the Febuxostat group (55.3\% of patients were females and $44.7 \%$ were males) and between the Allopurinol group regarding gender ( $58 \%$ of patients were males while $42 \%$ were females $),\left(\chi^{2}=5.337, p=0.021\right)$.

Regarding age, there was no statistically significant difference between the studied groups; the mean age in the Febuxostat group was $(61.54 \pm 12.40)$, while in the Allopurinol group the mean age was $(60.83 \pm 13.57)$. 
Regarding the comorbidities in patients; HTN was the most common comorbidity (90\%), combined DM with HTN in (44\%).

Regarding staging of CKD $43.3 \%$ of patients were in stage 3 while $56.7 \%$ were in stage 4 .

We compared baseline laboratory results including serum creatinine, eGFR, and serum uric acid. Regarding the creatinine the mean of the baseline serum creatinine in Febuxostat group was $2.36 \pm 0.86 \mathrm{mg} / \mathrm{dl}$, and for the patients in Allopurinol group was of $2.46 \pm 0.84$ $\mathrm{mg} / \mathrm{dl}$, there was no statistically significant difference between the two groups.

Regarding the baseline serum uric acid level; the mean of baseline serum uric acid level was higher in Febuxostat group than in Allopurinol group. $(u=9310.5, p=0.010)$.

Lee et al., $2019^{(65)}$ conducted a study on 141 hyperuricemic CKD patients stage 3. 30 patients treated with Febuxostat, 40 patients treated with Allopurinol and 71 received conventional CKD management only (control), the average follow-up period was 55.9 \pm 31.8 months, while the mean eGFR was $42.1 \pm 8.8 \mathrm{~mL} / \mathrm{min} / 1.73 \mathrm{~m}^{2}$. Data revealed that Febuxostat seems to reduce serum uric acid level and to retard renal disease progression more effectively than Allopurinol.

In the present study at 6 months and 12 months data revealed no significant difference in eGFR slopes between the Febuxostat and Allopurinol groups $(\mathrm{P}=0.461),(\mathrm{P}=0.100)$, respectively.

In line with our results that there is no significant difference regarding mitigation the decline of eGFR between Allopurinol and Febuxostat, Sezai et al., 2013 (NU-FLUSH trial) ${ }^{(66)}$ reported that there were no significant differences in eGFR between Febuxostat and Allopurinol (1month, $\mathrm{p}=0.1375$; 3months, $\mathrm{p}=0.3267$; 6 months, $\mathrm{p}=0.1132$ ) among 141 patients, Nevertheless the albuminuria levels measured were significantly lower in the Febuxostat group than the Allopurinol group after 3 and 6 months ( 3 months, $p=0.0449 ; 6$ months, $\mathrm{p}=0.0215$ ).

Tanaka et al., 2015 ${ }^{(67)}$ showed that there is no marked difference in eGFR between Febuxostat and conventional treatment (Allopurinol or no treatment) at 12 weeks but the decreases in L-FABP, urinary protein, b2MG level and urinary albumin were greater significantly with Febuxostat category than conventional treatment among 40 hyperuricemic CKD patients stage 3 . 
Kim et al., 2017 ${ }^{(68)}$ performed systematic review and meta-analysis involving four RCTs. While they found a marked difference between Allopurinol and Febuxostat group favoring Febuxostat $(\mathrm{p}=0.01)$ at 1 month, this difference disappeared at the 3 months follow up ( $\mathrm{p}=0.66$ ). Regarding the terms of albuminuria, a significant difference between Febuxostat and Allopurinol was found favoring Febuxostat $(\mathrm{P}=0.02)$.

In the FEATHER study, ${ }^{(69)}$ a large RCT, 443 CKD patients stage 3 were randomly assigned; 219 received Febuxostat and 222 received placebo. The mean eGFR did not differ significantly from one group to another $(\mathrm{P}=0.1)$. However, in patients without proteinuria and patients with creatinine lower than the median there was a significant beneficial effect from Febuxostat $(\mathrm{p}=0.005)$ and $(\mathrm{p}=0.009)$ respectively.

In the FREED study, $2019^{(70)}$ RCT was performed in 141 hospitals in japan among 1070 patients having potential risks for renal, cardiovascular or cerebral disease. Febuxostat was unable ameliorate the eGFR in comparison with non-Febuxostat group (if uric acid elevated during study patient would receive Allopurinol 100mg). However, it decreased the exacerbation of albuminuria or proteinuria and it has been speculated to exert a greater renoprotective effect than Allopurinol.

From the previous studies we found that although there wasn't significant amelioration of eGFR, there was evidence of decreased albuminuria and other inflammatory markers suggesting favorable effect of Febuxostat than Allopurinol.

In contrary to our results, there was a significant amelioration in eGFR with Febuxostat treatment than Alopurinol treatment in the following studies:

Sakai et al., 2014 ${ }^{(71)}$ reported that eGFR improved slowly in hyperuricemic CKD patients (eGFR $<60 \mathrm{~mL} / \mathrm{min} / 1.73 \mathrm{~m}^{2}$ ) who were resistant to Allopurinol after switching to Febuxostat treatment. During Febuxostat treatment, at all determined time points the changes in eGFR have been positive and the increase at 6 months was markedly significant $(\mathrm{p}=0.0027)$.

In our study, there was a reduction in serum uric acid level among all patient in both groups. Uric acid level decreased from $8.04 \pm 2.34 \mathrm{md} / \mathrm{dl}$ (baseline) to $5.37 \pm 1.59 \mathrm{mg} / \mathrm{dl}, 4.66$ $\pm 1.68 \mathrm{mg} / \mathrm{dl}$ at 6,12 months respectively in the Febuxostat group and for the Allopurinol group it decreased from $7.29 \pm 2.34 \mathrm{mg} / \mathrm{dl}$ (baseline) to $6.02 \pm 1.63,5.94 \pm 1.51 \mathrm{mg} / \mathrm{dl}$ at 6,12 months respectively. Reduction in uric acid level was significantly higher in Febuxostat group than Allopurinol group at 6 months $(\mathrm{u}=8644.5, \mathrm{p}=0.001)$ and 12 months $(\mathrm{u}=6316.0, \mathrm{p}$ 
$<0.001)$.

In line with our results Becker et al.,2005 reported that ${ }^{(72)}$ regarding urate lowering effect, usage of 80 or $120 \mathrm{mg}$ of Febuxostat was better than $300 \mathrm{mg}$ of Allopurinol $(\mathrm{P}<0.001)$. The primary outcome of the study was achieving serum urate level below $6 \mathrm{mg} / \mathrm{dl}$ at the last 3 months. This goal has been achieved in 53 percent of patients administered Febuxostat $80 \mathrm{mg}, 62$ percent of those administering Febuxostat $120 \mathrm{mg}$ and 21 percent of those administering Allopurinol $300 \mathrm{mg}$. This study conducted on 726 patients involving those having mild to moderate renal impairment.

Becker et al., 2009 conducted FOCUS trial ${ }^{(73)}$ on 1086 subjects including those with mild-moderate renal dysfunction with a follow up for 40 months. After 1 month $81 \%$ (501/620) of patients treated with $80 \mathrm{mg}$ Febuxostat and 87\% (241/277) of patients treated with $120 \mathrm{mg}$ Febuxostat achieved serum urate level less than $6 \mathrm{mg} / \mathrm{dl}$ in comparison with only $46 \%(64 / 139)$ of patients treated with Allopurinol. At the last visit on initial treatment, mean percentage reductions from baseline serum uric acid, analyzed, were $47 \%$ for Febuxostat 80 $\mathrm{mg}, 53 \%$ for Febuxostat $120 \mathrm{mg}$, and $32 \%$ for Allopurinol. Summarizing Febuxostat demonstrated superior urate-lowering efficacy of $80 \mathrm{mg}$ or $120 \mathrm{mg}$ compared to that of $300 \mathrm{mg}$ Allopurinol. 
Sezai et al.,2013 (NU-FLUSH trial) ${ }^{(66)}$ revealed that in comparison with Allopurinol Febuxostat has achieved a substantial early decrease of serum urate level in cardiac surgery patients having hyperuricemia.

Tanaka et al., 2015 ${ }^{(67)}$ performed a randomized prospective, parallel, open trial among hyperuricemic patients with CKD stage 3. 21 patients were assigned to be treated with Febuxostat and 19 patients received conventional treatment. The study period was 12 weeks. A significant higher reduction in serum urate level occurs in the Febuxostat group (-2.2 $\mathrm{mg} / \mathrm{dL})$ rather than conventional treatment $(-0.3 \mathrm{mg} / \mathrm{dl}),(\mathrm{P}<0.001)$.

Liu et al., $2019^{(74)}$ conducted a prospective study on 208 hyperuricemic CKD patients stages 3-5 (not on dialysis). Patients were assigned to receive Allopurinol $(\mathrm{n}=96)$ or Febuxostat $(n=112)$ and followed for 6 months. At the end of the study $96.4 \%$ of patients receiving Febuxostat achieved the target serum uric acid level $(<6 \mathrm{mg} / \mathrm{dl})$ while only $37.5 \%$ of patients receiving Allopurinol achieved this target. Thus, Febuxostat had superior uratelowering efficacy compared with Allopurinol group among Chinese Han CKD patients.

Actually, we couldn't find any study that show the reverse. All what we have found was favoring Febuxostat regarding urate lowering effect.

There is accumulating evidence which suggest that hyperuricemia is considered as an independent cardio-vascular risk factor which if corrected with XOI can decrease the risk of MACE. ${ }^{(75,76)}$

The potential CV (cardiovascular) benefits ascribed to xanthine oxidase inhibitor may be based on their anti-oxidant properties (by decrease production of reactive oxygen species which released during the activity of $\mathrm{XO}$ ) and/or the decrease in serum uric acid level. (75,76) Improvement in endothelial dysfunction markers has been demonstrated in experimental studies which test the cardiovascular effects of xanthine oxidase inhibitor. ${ }^{(77,78)}$

In the present study regarding occurrence of MACE;

In the Febuxostat group one patient developed anginal pain requiring PCI and stent insertion. 


\section{In Allopurinol group 3 patients developed the following events:}

1. Unstable angina for cardiac catheter but patient refused.

2. Non-stemi with 2 stents insertion.

\section{Inferior MI.}

There was no significant difference between Febuxostat and Allopurinol groups.

Similarly, to our results that Febuxostat wasn't significantly linked with a higher risk of MACE Becker et al., $2005^{(72)}$ reported that the serious adverse events occurred equally in both Febuxostat and Allopurinol groups. According to the investigator the adverse effects considered to be unrelated or unlikely to be associated to the study drug.

Becker et al.2010, ${ }^{(79)}$ conducted RCT on 2,269 subjects, among whom 65 percent had mild-moderate renal dysfunction. Data revealed there was no difference in adverse effects among the groups (Febuxostat 40mg, Febuxostat $80 \mathrm{mg}$ and Allopurinol). Adjudicated Antiplatelet Trialists Collaboration (APTC) event rate for Febuxostat $40 \mathrm{mg}$ was $0.0 \%$ and for both Febuxostat $80 \mathrm{mg}$ and Allopurinol was $0.4 \%$. All those who experience an APTC event had underlying risk factor for CVD or prior medical history of CVD. Also, the rates of nonAPTC cardiovascular events between treatment groups didn't differ significantly.

Foody et al.,2017, ${ }^{(80)}$ conducted a retrospective study on 2426 patients. Eligible patients (aged $\geq 18$ years) had to have gout, stage 3 or $4 \mathrm{CKD}$, and a history of CVD or HF. Data showed that the rate of MACE/1000 person-years in patients receiving Febuxostat was 51.8 and among those receiving Allopurinol was 99.3. Initiating Febuxostat drug was associated with a significant lower risk for MACE compared with those who received Allopurinol (the hazard ratio: $0.52 ; \mathrm{P}=0.02$ ).

Zhang et al.,2017, ${ }^{(81)}$ Performed a meta-analysis on 7757 patients including patients with impaired renal function, the follow up ranged from 2 to 172 weeks with a median 16 weeks. They aimed to evaluate the cardiovascular events of Febuxostat. The results revealed no significant difference between the two groups (Febuxostat versus Allopurinol, $\mathrm{p}=0.37$ ). Nevertheless, in long-term studies, the results were nearly significant, with more cardiovascular events occurring with Febuxostat drug.

The FREED study, ${ }^{(70)} 2019$ demonstrated that Febuxostat significantly reduced serum uric acid level, which was associated with reduction of cardiovascular, renal and cerebral events in comparison with conventional therapy (administration of $100 \mathrm{mg}$ of oral 
allopurinol was considered if serum uric acid was elevated during the study period) $(p=0.017)$, and the occurrence of MACE was similar in both groups.

In contrary to our results the occurrence of APTC was higher numerically but not significantly, among those who treated with Febuxostat $80 \mathrm{mg}$ and $120 \mathrm{mg} / \mathrm{day}$, in comparison with those who received Allopurinol 200mg or300 mg/day

The FDA released a public safety alert in response to the CARES study results; they reported no marked difference between Febuxostat and Allopurinol regarding occurrence of MACE (major cardiovascular event) in patients with gout having cardiovascular comorbidities at baseline however data reported that cardiovascular mortality and all-cause mortality were higher in Febuxostat than Allopurinol ( $\mathrm{p}=0.03, \mathrm{p}=0.04$ respectively). ${ }^{\left({ }^{82}\right)}$

In the present study there were no deaths among all studied patients in both groups.

In line with our results that Febuxostat doesn't have a higher risk of all- cause mortality Schumacher et al.,2008 ${ }^{(83)}$ performed the APEX trial, RCT trial and reported that there were no deaths at the end of the study among 1,072 hyperuricemic patients including those with decreased renal function (S.Cr 1.5 to $2 \mathrm{mg} / \mathrm{dl}$ ).

Becker et al., 2010 ${ }^{(79)}$ conducted CONFIRMS trial on 2269 subjects, 35\% of whom had mild to moderately impaired renal function. Data reported 5 deaths at the end of the study: 2 of them treated with Febuxostat, while 3 treated with Allopurinol. Investigators haven't found any deaths to be linked to the studied drugs.

In contrary to our results, other studies found that Febuxostat was associated with higher risk of all-cause mortality; the EXCEL trial, 2009, ${ }^{(84)}$ enrolled 1086 patients involving those with mild-moderate renal dysfunction for up to 40 months of follow-up. During the study ten subjects died including six deaths due to $\mathrm{CV}$ events, all of which were in the Febuxostat group. However according to the investigators, they didn't consider the events to be linked to the studied drug. 


\section{Conclusions}

\section{From this study, we conclude that in comparison with Allopurinol:}

- Febuxostat failed to mitigate the decline in eGFR significantly.

- Febuxostat has been more effective in lowering uric acid.

- Febuxostat wasn't associated with higher rate of MACE.

- Febuxostat wasn't associated with higher risk of cardiovascular death or mortality.

\section{Recommendations}

- Further prospective studies with large population sample are needed to assess renoprotective effect of Febuxostst in comparison with Allopurinol and determine their role in hyperuricemic CKD patients.

- Further prospective studies with large population sample are needed to assess cardiovascular risk of Febuxostat in comparison with Allopurinol and determine their effect in hyperuricemic CKD patients.

- Three arms; Febuxostat, Allopurinol and placebo are needed as the results will be more accurate with adequate recording of serum uric acid level in correlation with occurrence of side effects. 


\section{References}

1- Webster AC, Nagler EV, Morton RL, Masson P. Chronic Kidney Disease. Lancet 2017; 389(10075):1238-52.

2- Chapter 1: Definition and classification of CKD. Kidney Int Suppl (2011) 2013; $3(1): 19-62$.

3- K/DOQI clinical practice guidelines for chronic kidney disease: evaluation, classification, and stratification. Am J Kidney Dis 2002; 39(2 Suppl 1):S1-266

4- Fox CS, Matsushita K, Woodward M, Bilo HJ, Chalmers J, Heerspink HJ, et al. Associations of kidney disease measures with mortality and end-stage renal disease in individuals with and without diabetes: a meta-analysis. Lancet 2012; 380(9854):166273

5- Fujii H, Joki N. Mineral metabolism and cardiovascular disease in CKD. Clin Exp Nephrol 2017; 21(Suppl 1):53-63.

6- Nesrallah GE, Mustafa RA, Clark WF, Bass A, Barnieh L, Hemmelgarn BR, et al. Canadian Society of Nephrology 2014 clinical practice guideline for timing the initiation of chronic dialysis. Cmaj 2014; 186(2):112-7.

7- Khan S, Floris M, Pani A, Rosner MH. Sodium and Volume Disorders in Advanced Chronic Kidney Disease. Adv Chronic Kidney Dis 2016; 23(4):240-6

8- Abrams C, Accurso F, Afdhal N, Akin C, Aksamit A, Al-Awqati Q. Contributors. In: Goldman L, Schafer A (eds). Goldman's Cecil Medicine. $12^{\text {th }}$ ed. Philadelphia: W.B. Saunders; 2012. 3-30

9- Jin M, Yang F, Yang I, Yin Y, Luo JJ, Wang H, et al. Uric acid, hyperuricemia and vascular diseases. Front Biosci (Landmark Ed) 2012; 17:656-69.

10- Bardin T, Richette P. Definition of hyperuricemia and gouty conditions. Curr Opin Rheumatol 2014; 26(2):186-91.

11- Desideri G, Castaldo G, Lombardi A, Mussap M, Testa A, Pontremoli R, et al. Is it time to revise the normal range of serum uric acid levels? Eur Rev Med Pharmacol Sci 2014; 18(9):1295-306.

12- Zhu Y, Pandya BJ, Choi HK. Prevalence of gout and hyperuricemia in the US general 
population: the National Health and Nutrition Examination Survey 2007-2008. Arthritis Rheum 2011; 63(10):3136-41.

13- Lin KC, Lin HY, Chou P. Community based epidemiological study on hyperuricemia and gout in Kin-Hu, Kinmen. J Rheumatol 2000;27(4):1045-50

14- Mumford SL, Dasharathy SS, Pollack AZ, Perkins NJ, Mattison DR, Cole SR, et al. Serum uric acid in relation to endogenous reproductive hormones during the menstrual cycle: findings from the BioCycle study. Hum Reprod 2013; 28(7):1853-62.

15- Hak AE, Choi HK. Menopause, postmenopausal hormone use and serum uric acid levels in US women--the Third National Health and Nutrition Examination Survey. Arthritis Res Ther 2008; 10(5):R116.

16- Wyngaarden J, Kelley W. Epidemiology of hyperuricemia. In: Wyngaarden J, Kelley W (eds). Gout and hyperuricemia. New York: Grune \& Stratton; 1976. 21-37.

17- Ichida K, Matsuo H, Takada T, Nakayama A, Murakami K, Shimizu T, et al. Decreased extra-renal urate excretion is a common cause of hyperuricemia. Nat Commun 2012; 3(1):764.

18- Nugent CA, Tyler FH. The renal excretion of uric acid in patients with gout and in nongouty subjects. J Clin Invest 1959; 38(11):1890-8.

19- Kannangara DR, Ramasamy SN, Indraratna PL, Stocker SL, Graham GG, Jones G, et al. Fractional clearance of urate: validation of measurement in spot-urine samples in healthy subjects and gouty patients. Arthritis Res Ther 2012; 14(4):R189.

20- Perez-Ruiz F, Calabozo M, Erauskin GG, Ruibal A, Herrero-Beites AM. Renal underexcretion of uric acid is present in patients with apparent high urinary uric acid output. Arthritis Rheum 2002;47(6):610-3.

21- Dinour D, Gray NK, Campbell S, Shu X, Sawyer L, Richardson W, et al. Homozygous SLC2A9 mutations cause severe renal hypouricemia. J Am Soc Nephrol 2010; 21(1):64-72 
22- Jutabha P, Anzai N, Kitamura K, Taniguchi A, Kaneko S, Yan K, et al. Human sodium phosphate transporter 4 (hNPT4/SLC17A3) as a common renal secretory pathway for drugs and urate. J Biol Chem 2010; 285(45):35123-32.

23- Sánchez-Lozada LG, Soto V, Tapia E, Avila-Casado C, Sautin YY, Nakagawa T, et al. Role of oxidative stress in the renal abnormalities induced by experimental hyperuricemia. Am J Physiol Renal Physiol 2008; 295(4):F1134-41.

24- Choi YJ, Yoon Y, Lee KY, Hien TT, Kang KW, Kim KC, et al. Uric acid induces endothelial dysfunction by vascular insulin resistance associated with the impairment of nitric oxide synthesis. Faseb j 2014; 28(7):3197-204.

25- Mazzali M, Hughes J, Kim YG, Jefferson JA, Kang DH, Gordon KL, et al. Elevated uric acid increases blood pressure in the rat by a novel crystal-independent mechanism. Hypertension 2001; 38(5):1101-6.

26- Choi HK, Atkinson K, Karlson EW, Willett W, Curhan G. Alcohol intake and risk of incident gout in men: a prospective study. Lancet 2004; 363(9417):1277-81.

27- Choi HK, Atkinson K, Karlson EW, Willett W, Curhan G. Purine-rich foods, dairy and protein intake, and the risk of gout in men. N Engl J Med 2004; 350(11):1093-103.

28- Johnson RJ, Bakris GL, Borghi C, Chonchol MB, Feldman D, Lanaspa MA, et al. Hyperuricemia, Acute and Chronic Kidney Disease, Hypertension, and Cardiovascular Disease: Report of a Scientific Workshop Organized by the National Kidney Foundation. Am J Kidney Dis 2018; 71(6):851-65.

29- Bose B, Badve SV, Hiremath SS, Boudville N, Brown FG, Cass A, et al. Effects of uric acid-lowering therapy on renal outcomes: a systematic review and meta-analysis. Nephrol Dial Transplant 2014; 29(2):406-13.

30- Dincer HE, Dincer AP, Levinson DJ. Asymptomatic hyperuricemia: to treat or not to treat. Cleve Clin J Med 2002; 69(8):594, 7, 600-2 passim.

31- Yü T, Gutman AB. Uric acid nephrolithiasis in gout. Predisposing factors. Ann Intern Med 1967; 67(6):1133-48.

32- Yu TF. Urolithiasis in hyperuricemia and gout. J Urol 1981; 126(4):424-30.

33- Yamanaka H. Japanese guideline for the management of hyperuricemia and gout: second edition. Nucleosides Nucleotides Nucleic Acids 2011; 30(12):1018-29. 
34- Wortmann RL. Gout and hyperuricemia. Curr Opin Rheumatol 2002; 14(3):281-6.

35- Teng GG, Nair R, Saag KG. Pathophysiology, clinical presentation and treatment of gout. Drugs 2006; 66(12):1547-63.

36- Schlesinger N. Management of acute and chronic gouty arthritis: present state-of-theart. Drugs 2004; 64(21):2399-416.

37- Hung SI, Chung WH, Liou LB, Chu CC, Lin M, Huang HP, et al. HLA- B*5801 allele as a genetic marker for severe cutaneous adverse reactions caused by allopurinol. Proc Natl Acad Sci U S A 2005; 102(11):4134-9

38- Okamoto K, Eger BT, Nishino T, Kondo S, Pai EF, Nishino T. An extremely potent inhibitor of xanthine oxidoreductase. Crystal structure of the enzyme-inhibitor complex and mechanism of inhibition. J Biol Chem 2003; 278(3):1848-55.

39- Choi HK, Mount DB, Reginato AM. Pathogenesis of gout. Ann Intern Med 2005; 143(7):499-516.

40- Reiter S, Löffler W, Gröbner W, Zöllner N. Urinary oxipurinol-1- riboside excretion and allopurinol-induced oroticaciduria. Adv Exp Med Biol 1986; 195 Pt A:453-60.

41- Krenitsky TA, Elion GB, Strelitz RA, Hitchings GH. Ribonucleosides of allopurinol and oxoallopurinol. Isolation from human urine, enzymatic synthesis, and characterization. J Biol Chem 1967; 242(11):2675-82

42- Simmonds HA, Reiter S, Davies PM, Cameron JS. Orotidine accumulation in human erythrocytes during allopurinol therapy: association with high urinary oxypurinol-7riboside concentrations in renal failure and in the Lesch-Nyhan syndrome. Clin Sci (Lond) 1991; 80(3):191-7.

43- Krenitsky TA, Elion GB, Henderson AM, Hitchings GH. Inhibition of human purine nucleoside phosphorylase. Studies with intact erythrocytes and the purified enzyme. J Biol Chem 1968; 243(11):2876-81. 
44- Komoriya K, Hoshide S, Takeda K, Kobayashi H, Kubo J, Tsuchimoto M, et al. Pharmacokinetics and pharmacodynamics of febuxostat (TMX-67), a non-purine selective inhibitor of xanthine oxidase/xanthine dehydrogenase (NPSIXO) in patients with gout and/or hyperuricemia. Nucleosides Nucleotides Nucleic Acids 2004; 23(8-9):1119-22.

45- Takano Y, Hase-Aoki K, Horiuchi H, Zhao L, Kasahara Y, Kondo S, et al. Selectivity of febuxostat, a novel non-purine inhibitor of xanthine oxidase/xanthine dehydrogenase. Life Sci 2005; 76(16):1835-47.

46- Khosravan R, Grabowski BA, Mayer MD, Wu JT, Joseph-Ridge N, Vernillet L. The effect of mild and moderate hepatic impairment on pharmacokinetics, pharmacodynamics, and safety of febuxostat, a novel nonpurine selective inhibitor of xanthine oxidase. J Clin Pharmacol 2006; 46(1):88-102.

47- Mayer MD, Khosravan R, Vernillet L, Wu JT, Joseph-Ridge N, Mulford DJ. Pharmacokinetics and pharmacodynamics of febuxostat, a new non-purine selective inhibitor of xanthine oxidase in subjects with renal impairment. Am J Ther 2005; 12(1):22-34.

48- White WB, Saag KG, Becker MA, Borer JS, Gorelick PB, Whelton A, et al. Cardiovascular Safety of Febuxostat or Allopurinol in Patients with Gout. N Engl J Med 2018; 378(13):1200-10.

49- Burtis C, Ashwood E. Tietz textbook of clinical chemistry USA: Amer Assn for Clinical Chemistry; 1994.

50- Levey AS, Bosch JP, Lewis JB, Greene T, Rogers N, Roth D. A more accurate method to estimate glomerular filtration rate from serum creatinine: a new prediction equation. Modification of Diet in Renal Disease Study Group. Ann Intern Med 1999; 130(6):46170.

51- Eckel R, Grundy S, Zimmet P. The metabolic syndrome. Lancet 2005; 365(9468):1415-28.

52- Kamaya A, Wong-You-Cheong J. Diagnostic Ultrasound: Abdomen and Pelvis E-Book. London: Elsevier Health Sciences; 2015. 
53- Ohno I. Relationship between hyperuricemia and chronic kidney disease. Nucleosides Nucleotides Nucleic Acids 2011; 30(12):1039-44.

54- Sonoda H, Takase H, Dohi Y, Kimura G. Uric acid levels predict future development of chronic kidney disease. Am J Nephrol 2011; 33(4):352-7.

55- Mallat SG, Al Kattar S, Tanios BY, Jurjus A. Hyperuricemia, Hypertension, and Chronic Kidney Disease: an Emerging Association. Curr Hypertens Rep 2016; 18(10):74.

56- Kuwabara M. Hyperuricemia, Cardiovascular Disease, and Hypertension. Pulse (Basel) 2016; 3(3-4):242-52.

57- Siu YP, Leung KT, Tong MK, Kwan TH. Use of allopurinol in slowing the progression of renal disease through its ability to lower serum uric acid level. Am J Kidney Dis 2006; 47(1):51-9.

58- Goicoechea M, de Vinuesa SG, Verdalles U, Ruiz-Caro C, Ampuero J, Rincón A, et al. Effect of allopurinol in chronic kidney disease progression and cardiovascular risk. Clin J Am Soc Nephrol 2010; 5(8):1388-93

59- Shi Y, Chen W, Jalal D, Li Z, Chen W, Mao H, et al. Clinical outcome of hyperuricemia in $\operatorname{IgA}$ nephropathy: a retrospective cohort study and randomized controlled trial. Kidney Blood Press Res 2012; 35(3):153-60

60- . Halevy S, Ghislain P-D, Mockenhaupt M, Fagot J-P, Bouwes Bavinck JN, Sidoroff A, et al. Allopurinol is the most common cause of Stevens- Johnson syndrome and toxic epidermal necrolysis in Europe and Israel. J Am Acad Dermatol 2008; 58(1):25-32.

61- Stamp LK, O'Donnell JL, Zhang M, James J, Frampton C, Barclay ML, et al. Using allopurinol above the dose based on creatinine clearance is effective and safe in patients with chronic gout, including those with renal impairment. Arthritis Rheum 2011; 63(2):412-21.

62- Edwards NL. Febuxostat: a new treatment for hyperuricaemia in gout. Rheumatology (Oxford) 2009; 48 Suppl 2:ii15-ii9. 
63- Hoshide S, Takahashi Y, Ishikawa T, Kubo J, Tsuchimoto M, Komoriya K, et al. PK/PD and safety of a single dose of TMX-67 (febuxostat) in subjects with mild and moderate renal impairment. Nucleosides Nucleotides Nucleic Acids 2004; 23(89):1117-8.

64- Chohan S. Safety and efficacy of febuxostat treatment in subjects with gout and severe allopurinol adverse reactions. J Rheumatol 2011; 38(9):1957-9.

65- Lee J-W, Lee K-H. Comparison of renoprotective effects of febuxostat and allopurinol in hyperuricemic patients with chronic kidney disease. Int Urol Nephrol 2019; 51(3):467-73.

66- Sezai A, Soma M, Nakata K, Hata M, Yoshitake I, Wakui S, et al. Comparison of febuxostat and allopurinol for hyperuricemia in cardiac surgery patients (NUFLASH Trial). Circ J 2013; 77(8):2043-9.

67- Tanaka K, Nakayama M, Kanno M, Kimura H, Watanabe K, Tani Y, et al. Renoprotective effects of febuxostat in hyperuricemic patients with chronic kidney disease: a parallel-group, randomized, controlled trial. Clin Exp Nephrol 2015; 19(6):1044-53.

68- Kim S, Kim HJ, Ahn HS, Oh SW, Han KH, Um TH, et al. Renoprotective effects of febuxostat compared with allopurinol in patients with hyperuricemia: A systematic review and meta-analysis. Kidney Res Clin Pract 2017; 36(3):274-81.

69- Kimura K, Hosoya T, Uchida S, Inaba M, Makino H, Maruyama S, et al. Febuxostat Therapy for Patients With Stage $3 \mathrm{CKD}$ and Asymptomatic Hyperuricemia: A Randomized Trial. Am J Kidney Dis 2018; 72(6):798-810.

70- Kojima S, Matsui K, Hiramitsu S, Hisatome I, Waki M, Uchiyama K, et al. Febuxostat for Cerebral and CaRdiorenovascular Events PrEvEntion StuDy. Eur Heart J 2019; 40(22):1778-86.

71- Sakai Y, Otsuka T, Ohno D, Murasawa T, Sato N, Tsuruoka S. Febuxostat for treating allopurinol-resistant hyperuricemia in patients with chronic kidney disease. Ren Fail 2014; 36(2):225-31. 
72- Becker MA, Schumacher HR, Jr., Wortmann RL, MacDonald PA, Eustace D, Palo WA, et al. Febuxostat compared with allopurinol in patients with hyperuricemia and gout. $\mathrm{N}$ Engl J Med 2005; 353(23):2450-61.

73- Becker MA, Schumacher HR, MacDonald PA, Lloyd E, Lademacher C. Clinical efficacy and safety of successful longterm urate lowering with febuxostat or allopurinol in subjects with gout. J Rheumatol 2009; 36(6):1273-82.

74- Liu X, Wang H, Ma R, Shao L, Zhang W, Jiang W, et al. The urate- lowering efficacy and safety of febuxostat versus allopurinol in Chinese patients with asymptomatic hyperuricemia and with chronic kidney disease stages 3-5. Clin Exp Nephrol 2019; 23(3):362-70.

75- Richette P, Perez-Ruiz F, Doherty M, Jansen TL, Nuki G, Pascual E, et al. Improving cardiovascular and renal outcomes in gout: what should we target? Nat Rev Rheumatol 2014; 10(11):654-61.

76- Okafor ON, Farrington K, Gorog DA. Allopurinol as a therapeutic option in cardiovascular disease. Pharmacol Ther 2017; 172:139-50.

77- Higgins P, Dawson J, Lees KR, McArthur K, Quinn TJ, Walters MR. Xanthine oxidase inhibition for the treatment of cardiovascular disease: a systematic review and meta-analysis. Cardiovasc Ther 2012; 30(4):217-26.

78- Tsuruta Y, Kikuchi K, Tsuruta Y, Sasaki Y, Moriyama T, Itabashi M, et al. Febuxostat improves endothelial function in hemodialysis patients with hyperuricemia: A randomized controlled study. Hemodial Int 2015; 19(4):514-20.

79- Becker MA, Schumacher HR, Espinoza LR, Wells AF, MacDonald P, Lloyd E, et al. The urate-lowering efficacy and safety of febuxostat in the treatment of the hyperuricemia of gout: the CONFIRMS trial. Arthritis Res Ther 2010; 12(2):R63.

80- Foody J, Turpin RS, Tidwell BA, Lawrence D, Schulman KL. Major Cardiovascular Events in Patients with Gout and Associated Cardiovascular Disease or Heart Failure and Chronic Kidney Disease Initiating a Xanthine Oxidase Inhibitor. Am Health Drug Benefits 2017; 10(8):393-401.

81- Zhang T, Pope JE. Cardiovascular effects of urate-lowering therapies in patients with chronic gout: a systematic review and meta-analysis. Rheumatology (Oxford) 2017; 56(7):1144-53. 
82- White WB, Saag KG, Becker MA, Borer JS, Gorelick PB, Whelton A, et al. Cardiovascular Safety of Febuxostat or Allopurinol in Patients with Gout. N Engl J Med 2018; 378(13):1200-10.

83- Schumacher HR, Jr., Becker MA, Wortmann RL, Macdonald PA, Hunt B, Streit J, et al. Effects of febuxostat versus allopurinol and placebo in reducing serum urate in subjects with hyperuricemia and gout: a 28 - week, phase III, randomized, double-blind, parallelgroup trial. Arthritis Rheum 2008; 59(11):1540-8.

84- Becker MA, Schumacher HR, MacDonald PA, Lloyd E, Lademacher C. Clinical efficacy and safety of successful longterm urate lowering with febuxostat or allopurinol in subjects with gout. J Rheumatol 2009; 36(6):1273-82. 